\title{
Improvement of the technical excellence of multiparameter relay protection by combining the signals of the measuring fault detectors using artificial intelligence methods
}

\author{
A. L. Kulikov ${ }^{1}$, A. A. Loskutov ${ }^{1, *}$, and $M$. Mitrovic $^{1}$ \\ ${ }^{1}$ Power Supply and Power Electronics Nizhny Novgorod State Technical University n.a. R.E. Alekseev, Nizhny Novgorod, Russia
}

\begin{abstract}
The features of the dielectric rod defects and the rod-electrod defects of polymer insulators were investigated by using the developed complex method of contactless remote diagnostics of high-voltage insulators health, which includes the initial detection of local areas with elevated electric field gradients as well as measurement of a set of partial discharges characteristics. The radiation of extra-large partial discharges was detected and partial discharges features were investigated. According to the measurement results, a diagram was constructed for the electro-physical processes that accompany the emission of extralarge partial discharges; and the reasons for their occurrence were established.
\end{abstract}

\section{Introduction}

The increase in electricity demand, the complication of power systems and the use of modern technologies lead to the need to improve relay protection (RP). The use of microprocessor technology in RP devices provides the flexibility and versatility of their work. One of the modern directions in the evolution of RP is the development of multiparameter (multidimensional) algorithms [1-6]. Their basis is the use of multiple parameters of measured currents and voltages in the recognition of the operation modes of the electrical network. The redundancy of the information base of such RP provides the increase in the technical excellence of devices, including their sensitivity, reliability and speed.

\section{Relevance}

Increasing the sensitivity of relay protection is one of the actual tasks. This is especially important in recognizing emergency modes in modern power supply systems, including the presence of distributed generation sources. For example, the cause of low sensitivity (not recognizable damage) may be the presence of contact resistance in the place of short circuit currents (SC).

One of the effective methods of increasing the sensitivity is the use of multidimensional (multiparameter) RP based on the information approach [1-4]. There are developments of multiparameter protection, for example, for solving problems of longdistance backup with SC behind a transformer [5], as well as for determining the response parameters and combining the signals of individual starting organs [6-8]. In [9], the options for organizing the logical part of RP by automated synthesis based on the theory of automata were considered.

It is known to use methods of processing redundant information for RP and, in particular, voting schemes for increasing reliability [10-11]. Technical solutions of RP using artificial intelligence and machine learning, as well as algorithms for recognition of electrical network modes based on artificial neural networks (ANN) and decision tree (DT), were discussed in [12-18]. However, artificial intelligence methods were not used to organize the logical part of multiparameter RP.

\section{Purpose of the research}

The purpose of the article is to study and develop algorithms for the implementation of multiparameter RP using artificial intelligence methods, as well as algorithms that provide high levels of recognizability of emergency modes and reliability of operation by organizing the logical part of the device. In particular, the implementation of this purpose implies the precise determination of the triggering parameters (settings values) of individual measuring faults detectors (FD), as well as the effective combination of signals in the logical part of the multiparameter RP. This takes into account the minimization of instrumental and calculative costs. To form a multiparameter RP, a statistical approach is used, as well as pattern recognition procedures using ANN and DT methods.

\section{Statement of the task}

The use of the information approach in RP involves the multiple implementation of simulation of the electrical network and the protected object in normal and

\footnotetext{
* Corresponding author: loskutov.nnov@gmail.com
} 
emergency modes. The development of RP algorithms is based on model experiments [1-9]. In the course of research, the simulation model of the $220 \mathrm{kV}$ electrical network was used (Figure 1). It is implemented in the Matlab/Simulink software package (Figure 2). The model consists of three sections of a $220 \mathrm{kV}$ overhead transmission line, two power sources and a short-circuit connector through contact resistance in the reserve zone of protection RP1. The accumulation of measured current and voltage data was performed at the installation place of the RP1 at the beginning of the first section of the power transmission line (Figure 1). These data are necessary for the implementation and research of the developed RP.

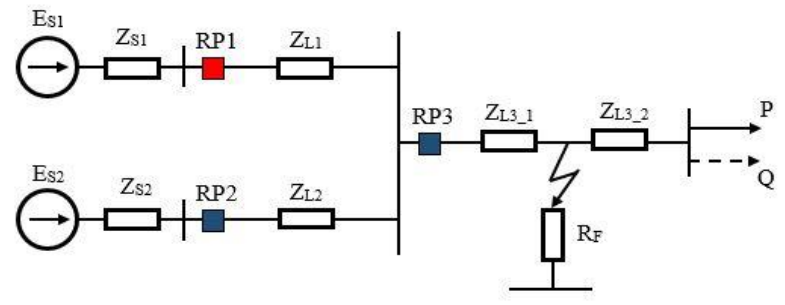

Fig. 1. The equivalent circuit of the observed section of the electrical network $220 \mathrm{kV}$.

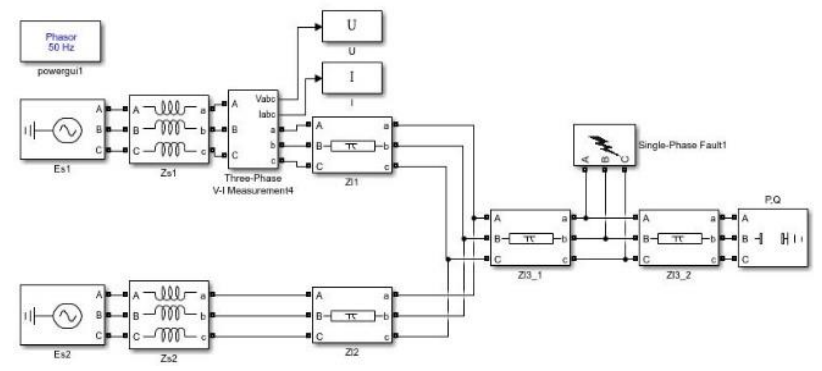

Fig. 2. Simulation model of the network segment in Matlab/Simulink.

The parameters of the elements of the simulation model are shown in table 1 . It must be emphasized, that during the operation of the network segment (Figure 1), the parameters of the elements may deviate from the specified values in the design. According to this, in order to obtain the required statistics on the network operation modes, the model parameters were divided into fixed and interval, that are varied in the specified ranges. The indices "1" and "0" (table 1) indicate the parameters of the positive and zero sequences.

Table 1 includes the following coefficients that specify the range of variation of the voltage of power systems and the angle of the phase shift between them:

$$
\begin{gathered}
k_{1}=E s 1 / U_{\text {nom }}, k_{2}=E s 2 / U_{\text {nom }}, \\
\delta=\arg (E s 1 / E s 2)
\end{gathered}
$$

To obtain the parameters of the statistical distributions of normal and emergency modes, simulation modeling implied 10000 iterations, including single-phase short-circuits along the third section of power line, which represents the backup zone of the observed protection RP1.

Multi-parameter relay protection was organized with the use of five separate one-dimensional measuring fault detectors: FD1 - by current module; FD2 - by voltage module; FD3 - by voltage phase; FD4 - by active power; FD5 - by reactive power. The obtained statistics data in the form of histograms for normal and emergency modes of each FD is approximated by a normal (Gaussian) distribution. On the graphs of the densities of the normal distribution, the horizontal axes represent the measurements of the observed parameters of the measuring FD in normal and emergency modes along power line 3 (Figure 3 ). The possibilities for recognizing the normal and emergency modes of the electrical network by a RP device are determined by the size of the area of intersection of the statistical distribution curves. Perfect, $100 \%$ recognizability, is carried out in the absence of the intersection of these curves.

\section{Proposed method}

To implement the methods discussed below, it is proposed to define the settings values by solving the statistical two-hypothetical task. It implies the implementation of the hypothesis testing procedure regarding the electrical network mode by each FD at the analyzed time point $\mathrm{t}$ : $\mathrm{H} 0$ - if the measurement belongs to the range of normal modes (output signal - "0"); H1 if the measurement belongs to the area of emergency modes (output signal - "1").

\begin{tabular}{|c|c|c|c|c|c|}
\hline \multicolumn{2}{|c|}{ Fixed } & \multicolumn{4}{|c|}{ Interval } \\
\hline Parameter & Value & Parameter & Value & Parameter & Value \\
\hline$U_{\text {nom }}(\mathrm{kV})$ & 220 & $X_{I}^{s l}(\mathrm{Ohm} / \mathrm{km})$ & $25.09( \pm 1)$ & line & $0.0001 \ldots 0.9999$ \\
\hline$L_{I}(\mathrm{~km})$ & 100 & $X_{0}^{s l}(\mathrm{Ohm} / \mathrm{km})$ & $1.31( \pm 0.1)$ & $R f(\mathrm{Ohm})$ & $0.1 \ldots 40$ \\
\hline$L_{2}(\mathrm{~km})$ & 100 & $X_{I}^{s 2}(\mathrm{Ohm} / \mathrm{km})$ & $9.75( \pm 1)$ & $\delta\left(^{\circ}\right)$ & $-30^{\circ} \ldots 30^{\circ}$ \\
\hline$L_{3}(\mathrm{~km})$ & 100 & $X \theta^{s 2}(\mathrm{Ohm} / \mathrm{km})$ & $0.87( \pm 0.1)$ & $K_{1}$ & $0.95 \ldots 1.05$ \\
\hline$b_{1}^{1,2,3}(\mathrm{~S} / \mathrm{km})$ & $\mathrm{j} 0.65 \cdot 10-6$ & $R_{I}^{l, 2,3}(\mathrm{Ohm} / \mathrm{km})$ & $0.13( \pm 0.01)$ & $K_{2}$ & $0.95 \ldots 1.05$ \\
\hline$b_{0}{ }^{l, 2,3}(\mathrm{~S} / \mathrm{km})$ & $\mathrm{J} 0.65 \cdot 10-6$ & $R_{0}{ }^{l, 2,3}(\mathrm{Ohm} / \mathrm{km})$ & $0.27( \pm 0.01)$ & $P(\mathrm{MW})$ & $300( \pm 10)$ \\
\hline$R_{I}{ }^{s 1, s 2}(\mathrm{Ohm} / \mathrm{km})$ & 0 & $X_{I}{ }^{1,2,3}(\mathrm{Ohm} / \mathrm{km})$ & $0.332( \pm 0.01)$ & $Q$ (MVar) & $150( \pm 10)$ \\
\hline$R_{0}{ }^{s l, s 2}(\mathrm{Ohm} / \mathrm{km})$ & 0 & $X_{0}{ }^{1,2,3}(\mathrm{Ohm} / \mathrm{km})$ & $0.332( \pm 0.01)$ & & \\
\hline
\end{tabular}

Table 1. Parameters of model elements. 


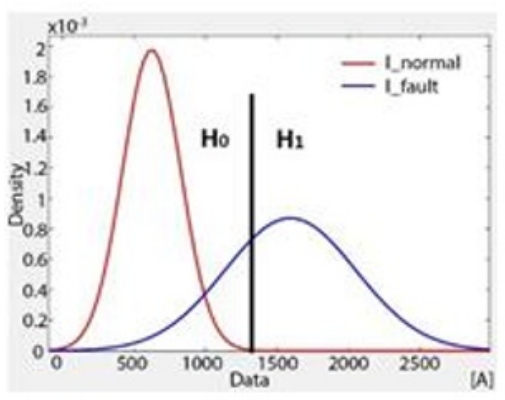

(a)

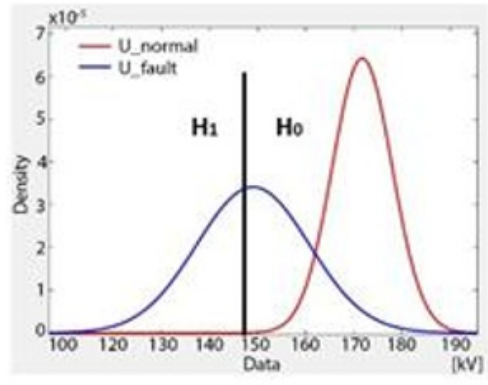

(b)

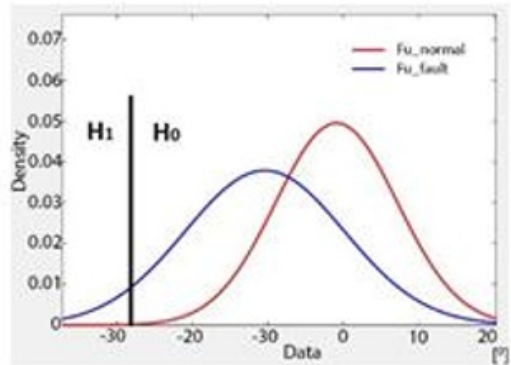

(c)

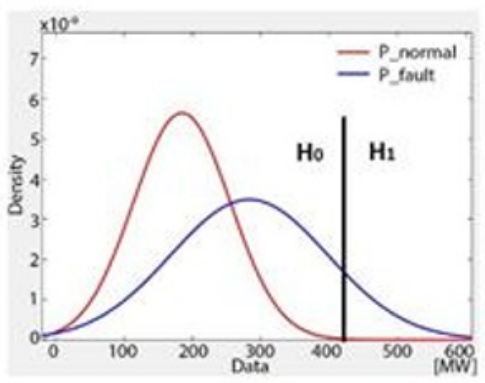

(d)

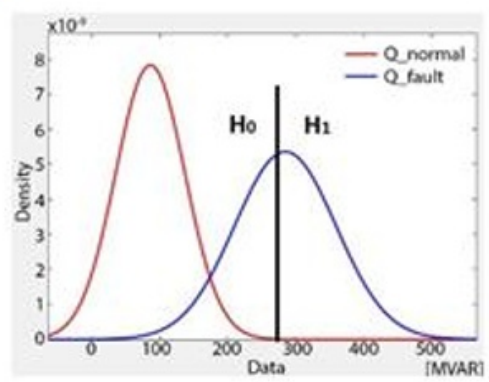

(e)

Fig. 3. Determination of setting values by detuning from normal modes: (a) FD1 - by current module, (b) FD2 - by voltage module, (c) FD3 - by voltage phase, (d) FD4 - by active power, e) FD5 - by reactive power.

\subsection{Determination of the parameters of the relay protection, based on the areas of normal and emergency modes}

The main requirement in determining the settings values of $\mathrm{PR}$ is to prevent protection operation in all possible normal modes. The determination of the settings values of each FD can be performed, for example, by the Baes criterion for minimizing the average risk of decision making [7-8]. In this case, the setting value $\eta$ must be set to a value that corresponds to a full detuning from all normal modes. In them, the RP should not operate (Figure 3).

Table 2. Probability of recognition of emergency modes of individual measuring fault detectors.

\begin{tabular}{|l|c|c|c|}
\hline $\begin{array}{c}\text { Measuring fault } \\
\text { detectors }\end{array}$ & Parameter & $\begin{array}{c}\boldsymbol{p}_{1} \\
(\mathbf{\%})\end{array}$ & $\begin{array}{c}\boldsymbol{q} \boldsymbol{1} \\
(\mathbf{\%})\end{array}$ \\
\hline FD1 - by current module & $I m$ & 73.78 & 26.22 \\
\hline FD2 - by voltage module & $U m$ & 43.16 & 56.84 \\
\hline FD3 - by voltage phase & $\varphi_{u}$ & 6.28 & 93.72 \\
\hline FD4 - by active power & $P$ & 12.14 & 87.86 \\
\hline FD5 - by reactive power & $Q$ & 56.07 & 43.93 \\
\hline
\end{tabular}

To determine the probability of the zones of triggering and not triggering belonging to the hypotheses $H_{0}$ (normal mode) and $H_{l}$ (emergency mode), features of the normal distribution of a continuous quantity were used [19]. Table 2 presents the probability of operation $\left(p_{1}\right)$ and non-operation $\left(q_{1}=1-p_{1}\right)$ of each FD for the curve belonging to the emergency mode. The probability of triggering $p_{l}$ corresponds to the area under the emergency mode curve belonging to hypothesis $H_{l}$, and the probability of non-triggering $q_{1}$ - the area under the same curve belonging to hypothesis $H_{0}$. Based on the above, the curve of normal modes completely belongs to the hypothesis $H_{0}\left(p_{0}=0, q_{0}=1\right)$.

\subsection{Combining of logic signals to RP protection modes using an artificial neural network}

The integration of logical signals at the outputs of measuring FD of RP is implemented using ANN and based on the Neural Net Pattern Recognition (nprtool) tool in the Matlab software package. For the training of the neural network, 14000 combinations of normal and emergency modes $(70 \%$ of the total sample loaded for experiments with ANN) were used. The combinations were randomly selected. Also, 3000 combinations (15\%) were used for validation and $3000(15 \%)$ for testing. The training was conducted on a simple neural network with one hidden layer of ten sigmoidal neurons, an input layer of five neurons and an output layer of two "softmax" neurons (Figure 4). Figure 5 illustrates the structural diagram for combining the logical signals of individual measuring FD using ANN.

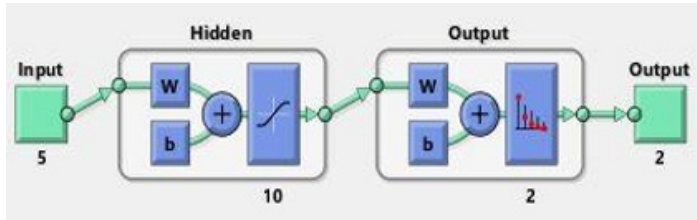

Fig. 4. Model of used ANN. 


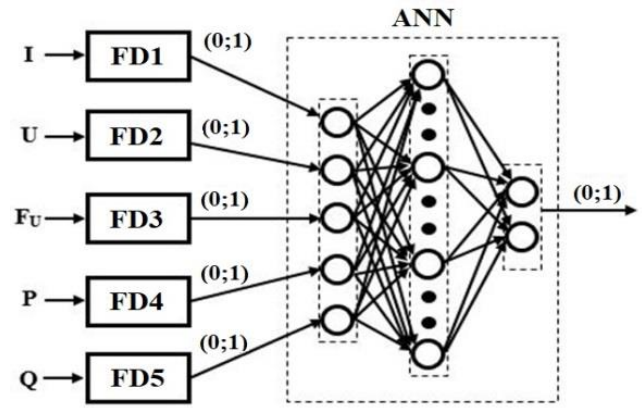

Fig. 5. The scheme of combining signals using ANN.

Training of the neural network model was achieved in 25 iterations with a duration of about $1 \mathrm{~ms}$. The final confusion matrix (figure 6) displays the ratio of recognizable and unrecognizable RP modes, as well as the number of used experimental measurements of normal $(10000=50 \%)$ and emergency $(10000=50 \%)$ modes.

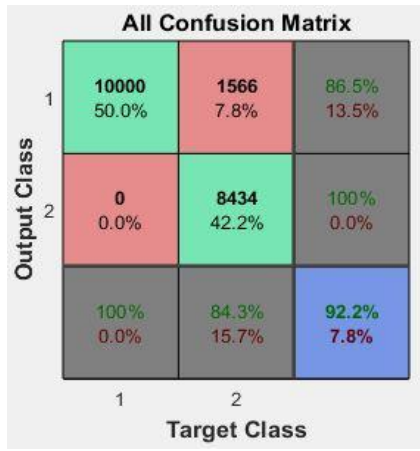

Fig. 6. ANN confusion matrix.

The element of the matrix $(1,1)$ represents the normal modes recognized by ANN, and (2.2) - the emergency modes. The element of the matrix $(1,2)$ characterizes the modes that are considered emergency. But during training, they turned out to be normal (incorrect recognition of emergency modes by RP). The field (2.1) corresponds to modes that were considered normal. But during training, they turned out to be emergency (incorrect recognition of normal modes by relay protection). From the analysis of figure 6 it can be seen that the complete detuning from the normal modes was performed correctly (the field (2.1) is 0). When combining signals in the logical part of multidimensional $\mathrm{RP}$, the recognizability of emergency modes has increased and is $84.34 \%$ (the value of the matrix element (2.2) is equal to 8434$)$.

\subsection{Combining logic signals from the outputs of measuring FD using the decision tree method}

The Matlab Classification learner application (fitctree) was used to combine the signals from the measuring FD and decide whether the relay protection was triggered or non-triggered. The classification of signals was carried out with 20000 observations that make up the database of parameters of the electrical network modes at the installation site of the RP1 protection. 10000 observations of emergency and 10000 observations of normal modes were made. The structure of the obtained decision tree and the signal combining scheme in the logical part are shown in figures 7 and 8 .

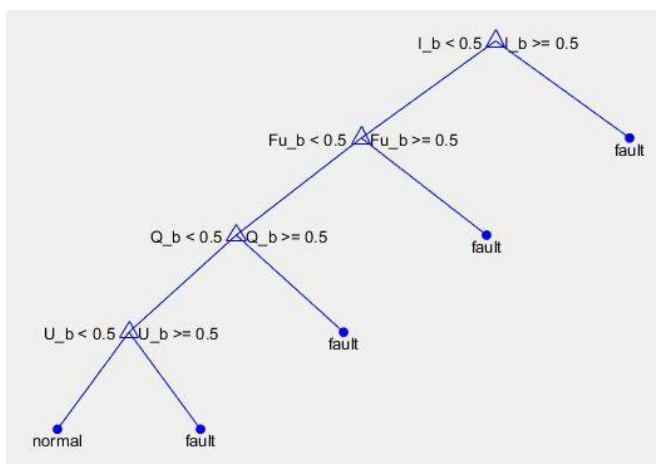

Fig. 7. Structure of the observed DT.

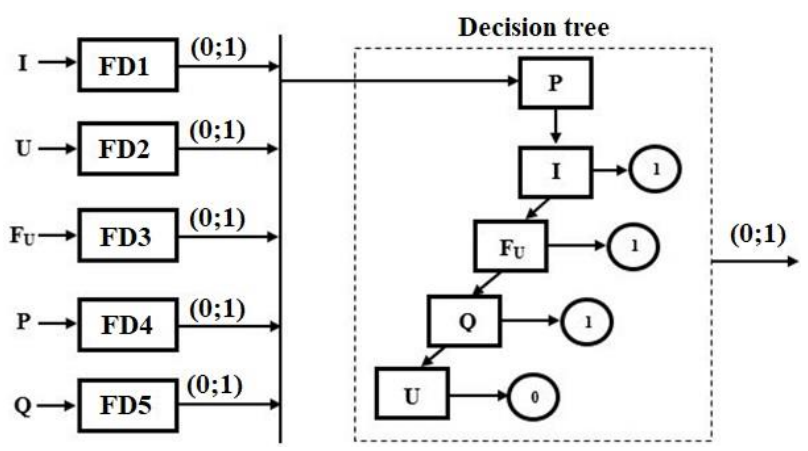

Fig. 8. Scheme of combining signals by the DT method.

From the analysis of the decision tree structure (figure 7), it was determined that when combining logical signals, only four measuring FD are sufficient. FD4 - by active power does not affect the increase in recognizability of modes in the relay protection device. This means that FD4 is also redundant in the formation of multiparameter relay protection in the RP1 location. Monitoring active power is optional. Thus, protection is simplified and its reliability is additionally increased, while maintaining high recognizability of emergency modes.

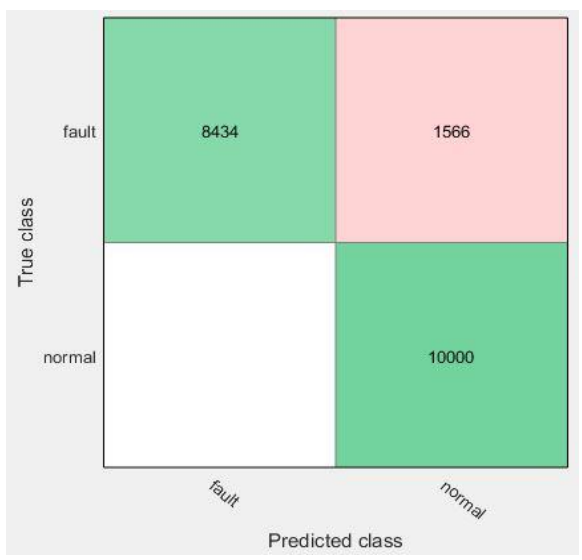

Fig. 9. DT confusion matrix.

Calculations of the confusion matrix of the DT (figure 9) show that it corresponds to the ANN confusion 
matrix. Diagonal fields (fault, fault) and (normal, normal) represent the correct recognition of emergency and normal modes. The field (normal, fault) represents the number of modes in which the RP malfunctions. It turned out to be zero. The number of unrecognized emergency modes was $15.06 \%$ (fault, normal). Thus, when combining logic signals from measuring FD using the DT method, protection will work correctly, and the recognizability of emergency modes increases to $84.34 \%$.

\subsection{Combined method}

To improve the reliability of multidimensional RP, it is proposed to organize the logical part of a protection device with a combination of ANN and DT methods based on the "1 of 2 " vote. To assess the reliability of such a logical part, a model of failures of unrecoverable systems was used. The combination of methods is carried out by parallel connection of their blocks (figure 10).

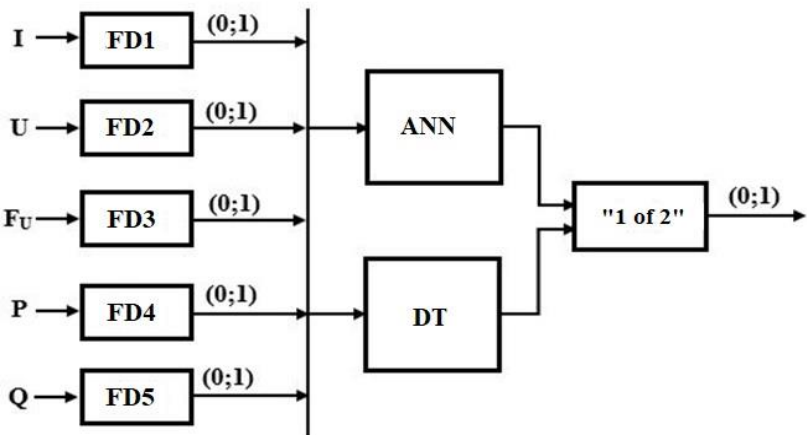

Fig. 10. The scheme of the logical part with the combined method.

Based on the fact that ANN and DT are considered as reliable methods, we suppose that the probabilities of reliable operation of the ANN and DT blocks (Figure 10) are the same. They correspond to the probabilities of microprocessor logic solvers (logic solver) used on objects of high security, for example, at nuclear power plants.

It should be noted that the probability of reliable operation of individual logical solvers is $99.4 \%$ during the operation period [20].

The failure model of unrecoverable systems implies that: $p_{i}(t)$ is the probability of failure of the $\mathrm{i}$-th system to work; $q_{i}(t)$ is the probability of failure of the $\mathrm{i}$-th system. Assuming that the methods (systems) have the same probability of failure-free operation during the exploitation of RP, $p_{l}(t)=p_{2}(t)=0.994$. The probability of failure is defined as:

$$
q_{i}(t)=1-p_{i}(t),
$$

As a result, it turns out that $q_{1}(t)=q_{2}(t)=1$ $0.994=0.006$. With parallel connection of logical blocks of the ANN and DT the probability of failure of the combined principle " 1 of 2 " of the system is

$$
q(t)=\prod_{i=1}^{n} q_{i}(t)
$$

The statement of numerical values in expression (3) leads to the probability of failure of the integrated relay protection equal to $q(t)=3.6 \cdot 10^{-5}$. On this basis, the probability of failure-free operation is $p(t)=1-q(t)=1$ $3.6 \cdot 10^{-5}=0.99996 \approx 100 \%$.

Thus, combining the methods of organizing the logical part of relay protection based on the "1 of 2" principle leads to a significant increase in the reliability of relay protection.

\section{Conclusions}

1. There have been analyzed the applicability of the methods of combining the signals of the logical part of multiparameter relay protection using artificial intelligence: ANN, DT and voting schemes according to the "1 of 2" principle. For the implementation of multiparameter relay protection, there were used the results of simulation of the electrical network and statistical techniques for processing the results of model experiments.

2. There was investigated a multiparameter relay protection with five individual one-dimensional measuring faults detectors. Measuring fault detector by current module (FD1) has the highest recognizability of emergency modes. The probability of recognition is $73.78 \%$. The combination of logical signals using the three proposed methods ensured an increase in the probability of recognizing an emergency mode to $84.34 \%$.

3. The choice of the method for combining the output signals of the measuring faults detectors in the logical part of the multiparameter relay protection is dependent on the characteristics of the electrical network modes and the requirements for the organization of the protection of the electric power facility.

The presented research results were obtained with the support of a grant from the President of the Russian Federation for state support of young Russian scientists (MK3210.2019.8). Agreement No. 075-15-2019-337 of 11.06.2019.

\section{References}

[1] Y.Y. Lyamets, G.S. Nudel'man, D.V. Zinov'yev, D.V. Kerzhayev, Y.V. Romanov, Mnogomernaya releynaya zashchita. CH.1. Teoreticheskiye predposylki Elektrichestvo 10, 17-25 (in Russian) (2009)

[2] Y.Y. Lyamets, G.S. Nudel'man, D.V. Zinov'yev, D.V. Kerzhayev, Y.V. Romanov, Mnogomernaya releynaya zashchita. CH.3. Ekvivalentirovaniye modeli Elektrichestvo 1, 9-15 (in Russian) (2009)

[3] Y.Y. Lyamets, G.S. Nudel'man, I.S. Podshivalina, Y.V. Romanov, Effekty Mnogomernosti v Releynoy Zashchite Elektrichestvo 9, 48-54 (in Russian) (2011) 
[4] S.V. Ivanov, Y.Y. Lyamets, Metod Informatsionnogo Analiza. Raspoznavaniye Zamykaniy v Zadannoy Zone Dvukhtsepnoy Elektroperedachi Izvestiya akademii nauk energetika 1, pp 47-57 (in Russian) (2016)

[5] I.V. Nagay, V.I. Nagay, Postroyeniye Mnogoparametricheskikh Rezervnykh Zashchit Elektricheskikh Raspredelitel'nykh Setey 6-10 kV Energetik 2, 18-21 (in Russian) (2013)

[6] M.V. Sharygin, A.L. Kulikov, The Effect of Combining Information of Relay Protection Fault Detectors Power Tech. and Eng. 52(5), 597-604 (2019)

[7] M.V. Sharygin, A.L. Kulikov, Automated Calculation and Coordination of Protective Relay Settings Power Tech. and Eng. 51(5), 593-601 (2018)

[8] A.B. Loskutov, M.V. Sharygin, A.L. Kulikov, A.A. Loskutov, Ensuring Relay Selectivity in Power Supply Systems using the Bayesian Method of Hypothesis Testing IJAER 12(24), 15420-31 (2017)

[9] A.L. Kulikov, A.A. Loskutov, M. Mitrovic, Method of automated synthesis of the logic part of relay protection device which increases its sensitivity Int. ScTech Conf. ISEPC-2019 (23-24 May 2019, St. Petersburg, Russia) (2019)

[10] J. McCalley, O. Oluwaseyi, V. Krishnan, R. Dai, C. Singh, K. Jiang, System Protection Schemes: Limitations, Risks, and Management PSERC 10-9 (2010)

[11] IEEE PSRC WG I-19 Redundancy Considerations for Protective Relaying Systems (2008)

[12] M. Lukowicz, E. Rosolowski, Fault type classification in high voltage power systems using artificial neural networks Wroclaw University of Technology (Poland) 1-6 (1996)

[13] M.M. Saha, E. Rosolowski, J. Izykowski, 2001 Artificial Intelligent Application to Power System Protection ResearchGate 595-600

[14] Y.Y. Hong, P.C. ChangChian, Detection and correction of distorted current transformer current using wavelet transform and artificial intelligence Inst. Eng. Technol. Gen. Transm. Distrib, 2(4), 566-75 (2008)

[15] N. Singh, H.K. Verma, S. Deb, Development of ANN Based Relay Algorithm for Protection of Series Compensated Transmission Line IOSR J of El. and Elect. Eng. (IOSR-JEEE) 11(4), 74-82 (2016)

[16] S.R. Samantaray, I. Kamwa, J. Geza, Decision tree based fault detection and classification in distance relaying Int. J. of Engin. Intel. Sys. for Elect. Eng. and Comm 18(2), 1-9 (2011)

[17] J. Azarakhsh, The Power Transformer Differential Protection Using Decision Tree Bulletin de la Société Royale des Sciences de Liège 86, 726-38 (2017)

[18] S. Netsanet, J. Zhang, D. Zheng, Bagged Decision Tree Based Scheme Of Microgrid Protection Using Windowed Fast Fourier and Wavelet Transforms Electronics 7(61), 1-25 (2018)

[19] Ž. Zrno, Neke primjene normalne (Gaussove) distribucije Zbornik radova Međimurskog veleučilišta u Čakovcu, 2(2), 129-43 (in Serbian) (2011)

[20] H. Hemark, New Electrical Devices in Existing Nuclear Power Plants REPORT 445,18 (2017) 